\title{
Watchful waiting in the world we inhabit
}

Previously published at www.cmaj.ca

\section{Living Downstream}

Chandra Chevannes, director

Sandra Steingraber PhD

The People's Picture Company; 2009.

$\mathrm{T}$ he words 'watchful waiting' are uttered several times in Living Downstream, a thoughtful, engaging documentary about bladder cancer survivor, biologist and ecological activist, Sandra Steingraber. Specifically, these words refer to the period after her annual cancer checkup, an unsettling and ambiguous time when she waits for test results while attending carefully to any perceptible shifts in her body's condition. As Steingraber describes it, this is a form of heightened body consciousness, a visceral awareness that takes her through periods of anxiety, fatalist anticipation and, finally in her case, relief. Beyond the immediacy of this phrase to the life and work of Steingraber, known in some circles as the "poet laureate of the environmental health movement," it also resonates as an underlying theme of this film. Individually and collectively, we should all adopt a state of "watchful waiting' about the world we inhabit and actively investigate the rush toward 'progress' that is demonstrably endangering our environment and, eventually, as she and other scientists contend, our bodies.

Part personal narrative, part political pamphlet, part philosophy of medicine, Living Downstream is a deftly interwoven examination of how cancer is experienced, treated and understood. The film is based on Steingraber's eponymous bestselling book first published in 1998 and reprinted in 2010. As her voice-over narration states at the outset, this is film that is "going up the river of cancer" to try to identify its complex origins. Unlike the indignant hectoring tone of a documen-

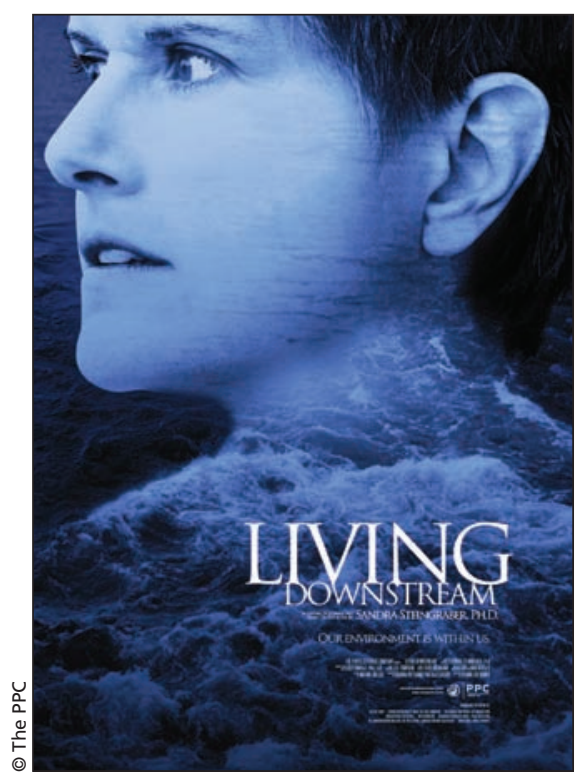

tarian like Michael Moore (for example, see his 2007 film about the US medical system, Sicko), Canadian filmmaker Chandra Chevannes adopts a more meditative approach, quietly illuminating the scientific evidence Steingraber presents and her impassioned arguments in discussions with other scientists, her husband and her mother, also a cancer survivor. Her principal challenge to medical practitioners, oncologists and others, is to expand the conversation about cancer to include a serious and sustained consideration of environmental factors.

Structured around a personal narrative in which Steingraber travels to speaking engagements at health conferences while she waits to hear about the results of her latest cancer tests, Living Downstream tackles the political and even philosophical challenges presented by the reality that our society and economy appears dependent upon the industrial-scale production of chemicals and carcinogens. As Steingraber puts it, who decides how much harm is tolerable? The stakes are high, in her words: "This is about people's lives being wrecked or being saved."
These arguments derive from and are clearly driven by her personal story of cancer survival. Born in 1959 and raised in Illinois, Steingraber was diagnosed with bladder cancer at the age of 20 . After successful treatment, she went back to university, eventually earning a doctorate in biology. Shaped by her experience with cancer, she then began to research its possible causes beyond the usual determinants, such as genetic predisposition and lifestyle. Inspired by wildlife biologist and public health pioneer, Rachel Carson (whose 1962 book, Silent Spring, sounded the alarm about the extensive use of DDT and other chemicals in postwar North America), she pored over extensive data on fertilizers and pesticides used on Illinois farmlands.

While the links to increased cancer rates are not direct, Steingraber insists that the significant and ongoing presence of chemical agents such as Atrazine in the soil and water tables must be a contributing factor. Like other scientists and doctors from California to Cape Cod who appear in the film, she says that she is a person "putting jigsaw puzzles together" and observing "... arrows of evidence pointing in the same direction." And those arrows invariably point, literally and metaphorically, upstream.

From the community "cancer cluster' in Normandale, Illinois, to the Salinas River in California where scientists discover that pesticide run-off is causing gender transformation in frogs, to the northern New Hampshire's White Mountains where leaf litter contains high levels of PCBs, to Montréal where beluga whales who swim near an aluminum smelter are ridden with cancers and cysts, the evidence mounts. The strength of this film is that it places this evidence in a broader socio-economic and political context, echoing the perspective of interconnectedness advocated by Steingraber herself. Indeed, all of these elements converge in questions 


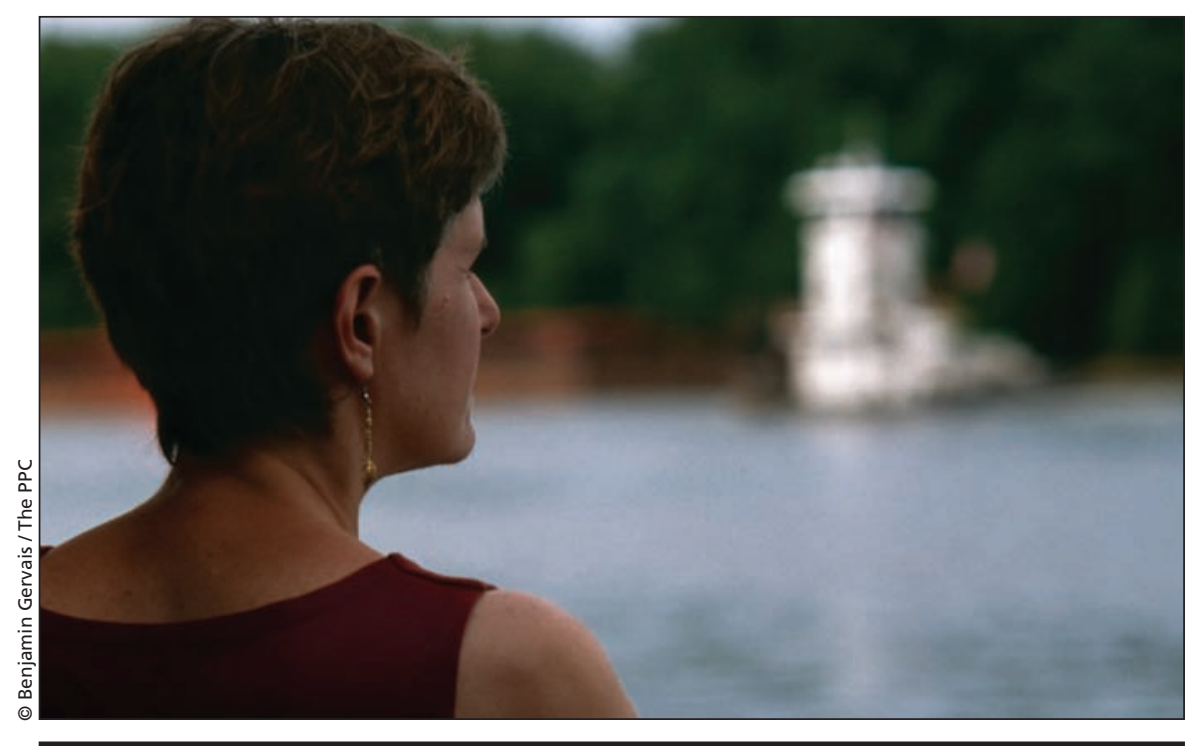

Sandra Steingraber on the bank of the Illinois River.

about prevailing philosophies of cancer treatment. Whether or not one agrees completely with her assertion that 'cancer prevention is a human rights issue' (like all activists, Steingraber does occasionally slip into evangelical mode), it is difficult to ignore the larger questions raised by her work.
Like other contemporary Canadian documentaries (see especially fellow Canadian Kevin McMahon's recent documentary on the Great Lakes, Waterlife), Living Downstream presents a holistic view, asserting that the world is a place where everything is connected. In this case, the underlying argument is that it is irresponsible to discount largely unseen, but ubiquitous environmental factors in the causation of cancer.

Ultimately, and despite its lack of a self-critical dimension, Living Downstream should not be understood as a documentary claiming to provide answers or specific diagnoses, but rather as a forceful, reasoned and visually impressive presentation of a compelling argument that demands further consideration, discussion and exploration. In one sense, it is itself an artifact of 'watchful waiting' and is worthy of attention, if only to broaden the crucial conversations to be had between those who have cancer and those who treat it. After all, as Steingraber and other scientists and physicians argue, our silence will not protect us.

\section{Tom McSorley}

Executive Director

Canadian Film Institute

Ottawa, Ont.

Tom McSorley is a sessional lecturer in the Department of Film Studies at Carleton University, Ottawa, Ont. and film critic for CBC Radio One's, Ottawa Morning.

\section{Creative works}

\section{The psych consult}

Previously published at www.cmaj.ca

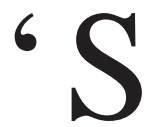
tat consult for 55-year-old white female in room 12 , agitated patient throwing food trays at nursing staff," reads the text message on my pager.

I'm disappointed. It's six o'clock on a Saturday evening. I had just left the hospital and was driving home. The urgency of the consult forces me to turn my car around and abandon my dinner plans.

In the doctor's lounge, I take a few moments to review the patient's electronic record. My disappointment turns to irritation as I scan the entries: "multiple admissions," "unexplained abdominal pain, likely irritable bowel syndrome," "negative workups," "pending litigation outcome."

My irritation grows as I take the elevator to the 12 th floor. I overhear a nurse talking to a student in the hallway as I head toward room 12. "Can you believe her? She's acting as though irritable bowel syndrome is gonna kill her!" she exclaimed. Her trainee rolls her eyes in agreement.

I stop walking. The urgency of the consult, the hopeless chart entries, the exasperated nurse, my disappointment and irritation - it is all an indicator of how the patient is feeling. Her psychological distress is infiltrating all those around her.

My irritation at my disrupted dinner plans made me miss this clinical sign. As a psychiatric consultant, I should have known better.

For the second time that day, I turn directions and head to the nurses' station. Moments later the nurse, her student and I sit in a triad. I hear about their challenging day caring for this patient, her relent- less requests and questions about her diagnosis and its treatment. Her dramatic posturing when in pain, so flagrant that she accidently knocked an uneaten dinner tray off a table, its hot contents splattering all over a nurse's aide. The last straw.

"Tough patient," I offer sympathetically.

The nurse nods and adds with an embarrassed tone, "I didn't mean to talk so loudly in the hallway. I just felt frustrated."

Back on course, I head toward the patient's room. I pause at the open doorway before knocking. Inside the darkened, quiet room she lay. A middle-aged woman, on her back, both hands resting on her belly, eyes closed, moaning quietly. I scan the room for flowers, cards, or slippers from home, the obligatory items people bring when a loved one is hospitalized. Nothing. 